Vol. 5, Issue.1, Jan-Feb 2022, page no. 08-20

To cite this article: Dr Edward Maina Andafu and Dr Hardley Musiega Sogoni (2022). INTERROGATION OF THE TEACHERS SERVICE COMMISSION'S PROPOSED TEACHER EDUCATION REFORMS IN KENYA: A COMPARATIVE PERSPECTIVE OF INTERNATIONALLY ACCEPTABLE STANDARDS, International Journal of Education and Social Science Research (IJESSR) 5 (1): 08-20

\title{
INTERROGATION OF THE TEACHERS SERVICE COMMISSION'S PROPOSED TEACHER EDUCATION REFORMS IN KENYA: A COMPARATIVE PERSPECTIVE OF INTERNATIONALLY ACCEPTABLE STANDARDS
}

\author{
Dr Edward Maina Andafu ${ }^{1}$ and Dr Hardley Musiega Sogoni ${ }^{2}$ \\ ${ }^{1,2}$ Lecturer, Department of Educational Foundations \\ Kenyatta University \\ P.O. Box 43844-00100 \\ Nairobi
}

DOI: http://dx.doi.org/10.37500/IJESSR.2022.5102

\begin{abstract}
Currently global teacher education dynamics have triggered debates on what need to be done to enhance this noble profession. The political class has triggered duress conflict cutting across different governmental institutions comprising of the education ministries, universities and teacher education colleges. The objective of this article was: 1) To examine the Current trends on the quality and acceptable standards of Teacher Education, 2) To comparatively critique the existence of Bachelors degree in education among different countries and, 3) To conduct comprehensive analysis of other Legal documents on teacher development programmes in Kenya. This article focuses on quality teacher education programmes and hence suggests a unified conceptual framework for quality teacher education to facilitate an understanding of teacher education training. The suggested conceptual framework is multi-dimensional in nature and based on operational experience by the authors studying education systems' performance in general, and particularly, quality of education in Universities. The unified conceptual framework invoked here is informed by systems theory and acknowledges the interdependence among the components of quality of education and levels of the education system. This paper undertook an eagle's eye view of modern society's Teacher Education legal framework in respect to the TSC's proposed recommendations on the Teacher Education programmes in Kenya. Findings of the study reveal existence of sound modalities' invoked by civilized societies in reviewing the teachers' curriculum offered by different teacher education institutions. It is recommended that any attempt to review Teacher Education programme in Kenya should comply with the international and morally acceptable mechanisms.
\end{abstract}

KEYWORDS: Curriculum review, Teacher Education, Teachers Service Commission 


\section{INTRODUCTION}

Globally, Teacher Education is regarded as prerequisite for the provision of high quality education and much needed service at all levels. The key objective of teacher education is to produce academically excellent and professional individuals to handle education tasks. The quality of teacher's education programmes is pegged on the availability of qualified and motivated human capital, a curriculum that is both appropriate and focused on enhancing education endeavours (Sifuna and Oanda, 2014). During the 2000 Dakar Education for All Conference (EFA), a number of deliberations were made. The conference came up with six key goals that the African governments were to integrate into their education framework. Of key interest is the sixth goal that addresses the need for quality education for economic development. This sixth goal articulates fundamental elements such as provision of adequate funds for the education sector, establishment of quality assurance, recruitment and deployment of teachers, the quality of teaching personnel and capacity development in pedagogical skills (Sifuna and Oanda, 2014). Internationally, the review of any teachers training programme aims at fulfilling either teacher's mastery of content or enhancing of the pedagogical skills. In Finland for instance, the competition to secure admission to teacher education programme is enormous, and only 15 percent of the applicants are accepted. The selection policy for classroom and subject teacher applicants entails studying education as a major subject and admission to respective subject in another faculty which usually commence after two years (UNESCO, 2003).

In view of the dynamics witnessed globally, the Kenyan government envisaged to enact amendment to the teacher's education programme. However, the proposed review of the Teacher Education Programmes by the TSC has drawn sharp criticism and controversy among stakeholders in the Kenya's education sector. Although the commission appear to act within its mandate as enshrined in the constitution and the TSC Code of Regulations, the procedure used to formulate the recommendations and its failure to involve all the stakeholders in the whole process casts doubt on the motive of the whole exercise. This paper seeks to interrogate the TSC's proposals to effect fundamental changes in the Teacher Education programme in Kenya against the internationally best practices of curriculum review and implementation in the teacher education institutions. This paper consists of four sections. Section one examines current international trends on the quality and standards of Teacher Education while section two constitutes a comparative overview of the Framework on the Teacher Education programmes. Analysis of the main themes of the study and recommendations for a morally acceptable mechanism for curriculum review process, based on internationally acceptable standards are contained in section three.

\section{Current International trends on the quality and standards of Teacher Education}

Teacher education in Croatia is placed into two categories namely, the teachers' colleges and university faculties (UNESCO, 2003). According to the Croatian state, the teachers' colleges train pre-primary and lower primary school teachers whereas university faculties are mandated to facilitate subject teachers for upper primary and secondary school level. The Croatian government through the 
university faculties are empowered and established to manage the Teacher Education programmes. For instance, at the university; there are thirteen teacher education departments that train teachers and experts in academic discipline (Vizek-Vidovic et al.2000). One of the salient features of teacher education reforms in Croatian is the emphasis that reforms on teacher education should be based on educational theory and based on research on educational sciences.

In Finland, the teaching profession is one of the most competitive careers. Teacher selection is competitive to the extent that only $15 \%$ of the potential applicants are accepted. The recruitment condition for classroom and teacher applicant is quite diverse in the sense that those who intend to be trained as classroom teachers have to major in education courses. The second option of becoming a teacher is through subject content education which must be accompanied by Teacher Education lasting for two years (UNESCO 2003). This explains why Finland is highly rated for its efficacy and professionalism in their education system. Additionally, the eight Universities in Finland have Teacher Education programmes for the classroom teachers and for the subject teachers (Tella, 1996.) In essence teacher education programmes are highly valued in Finland. Their efficacy in education is founded on pedagogical studies worth of thirty-five credits for the prospective educationists. Of expedient to state, the quality of education is the greatest philosophy of the Finnish education system. For instance, a Bachelors Degree in education and pedagogical studies are the requirements for one to qualify as Kindergarten teachers. In contrast to Finland, very few Kindergarten schools in African have teachers with Bachelors degree certificates in education.

Anecdotal evidence reveals that quality education has a direct link to Teacher Education programmes. In its search for enhancement of teacher professionalism, the Teachers Service Commission is enshrined in Article 237 of Kenyan constitution. Article 237 (2) of the constitution empowers the commission to review the standards of education and training of persons entering the teaching service, review the demand and supply of teachers then advise the national government accordingly (Republic of Kenya, 2010). In line with the Constitution of Kenya, Article 43 of the Teachers Service Commission Code of Regulations for teachers stipulates that TSC is mandated to develop and review the entry qualification to various levels of Teacher Education training programmes. To this effect, it is supposed to partner with the institutions responsible for designing Teacher Education curriculum and provide guidance and support when need arises (Republic of Kenya, 2015).

It is with reference to the said mandate that TSC sought to institute changes in the Teacher Education and training programmes with effect from September 2021. The change comprises a review of the structure and curriculum in the Teacher Education institutions at all levels, as well as the entry qualifications to the Teacher Education courses. This was a response to the need to offer quality education training to its teacher's, based on the national conference held in 2005. It is worthy to note that the sessional paper number 1 on Education and Training stressed the importance of restructuring teacher education with the aim of enhancing quality and deployment strategies (Kenya, 2005). The 
2005 sessional paper NO. 1 policy opined that a continuous enhancement in quality services was necessary. The sole objective of this policy was to:

1) Address existing weaknesses in teacher quality and to facilitate pedagogical skill acquisition

2) Develop new teachers training policy that focuses on modern teacher training policy based on projected needs

3) To develop pedagogical curriculum for each level of educational system to place emphasis on child-centred practices.

Although the move by TSC appears to be within its mandate, the function of curriculum review is bestowed upon the Kenya Institute of Curriculum Development (KICD). Among other functions of KICD is to develop, review and approve programmes, curricula support materials for basic education and tertiary institutions (Republic of Kenya, 2013). However, the scope of KICD's operation excludes universities since they are autonomous (Githiga, 2012). The role of determining academic programmes offered in the university is the sole prerogative of the University Senate in liaison with the regulations of the Commission for University Education (CUE). The Senate monitors and regulates university's academic standards and programmes. This includes but not limited to determining academic courses to be offered, eligibility of persons for admissions to programmes of study and deciding on the persons who have attained the prescribed standard for conferment with degrees and award of Diplomas and Certificates (Republic of Kenya, 2012). The TSC's mandate is thus limited to reviewing and advising on the standards of education and training of persons entering the teaching service in Kenya. However, TSC overstepped its mandate and made recommendations to be adopted in the Teacher Education curriculum regardless of the due process.

\subsection{OBJECTIVES}

\subsection{General Objective}

The article was guided by the need of examining the Teachers Service commission suggested teachers legal framework on teachers training in Kenya.

\subsection{Specific Objectives}

This article intends:

1. To examine the Current trends on the quality and acceptable standards of Teacher Education

2. To comparatively critique the existence of Bachelors degree in education among different countries

3. To conduct comprehensive analysis of other Legal documents on teacher development programmes in Kenya. 


\subsection{THEORETICAL FRAMEWORK}

The conceptual framework for quality of education in schools proposed here (see Figure 1) is based on systems theory applied to education. This theory is important for understanding any education system for it contrasts with numerous fragmentary reforms aimed at improving aspects or parts of the education system which may not normally succeed (Barile \& Polese, 2010). This theory derives its notion from science, where it is believed that a set of parts of a system interact to achieve specified objectives (Banathy \& Jenlink, 2004; Wright, 2008). Similarly, in an education system, various levels of the education system (national, tertiary, school, and pre-school) and their associated classrooms, together with their relevant stakeholders, should work together to achieve systemic educational goals. This involves developing relevant monitoring and evaluation instruments for use in monitoring and evaluating education to find out whether quality is being realized, which should be a joint effort of all education stakeholders. In our proposed conceptual framework for quality of education, SSE is a central component at all the levels, where the national level should design and develop an SSE framework (see Figure 1). After its evaluation to ascertain its quality, this SSE framework should be given to schools, where it should be used to do the actual SSE in the school as well as in classrooms. After the SSE, an SSE report, which will be a description of the evaluation's findings, will be produced (see Figure 1). The SSE report will also highlight what needs to be improved to enhance quality of education in the school. So, SSE is a crucial component for quality improvement as shown in Figure 1. Failure to realize educational goals may be unfitting to assume that problems may be at any one of the levels of the education systems. Instead, a comprehensive analysis of the education system should be done to understand the problem and to find out the exact source of the problem. This may help to ensure effective improvement to take place. To this effect, Mele et al. (2010) suggest that when working with systems, we should explore critically the problem itself with all those who are affected by it. This may help to ensure an effective solution to the problem. Without a comprehensive systemic approach to solving educational problems, improvements may only be based on trial and error which may fail to address the problems. Furthermore, general solutions to educational problems may not necessarily work since each education system is unique. Unfortunately, very few people are trained in systems theory approach to research in education. Considering systems' theory approach to education, the conceptual framework for quality of education in schools proposed here acknowledges a bidirectional influence of quality of education among the different levels of the education system, whereby the quality of education at one level will influence that of the other levels and vice versa

\section{The Proposed Conceptual Framework for Quality of Education}

Our proposed conceptual framework for quality of education in this article (see Figure 1) is based on an input, process, output approach, where these should be specified at every level of the education system namely, the national, pre-school, tertiary, and school levels. The consideration of inputs, processes, and outputs at every level of the education system in conceptualizing quality of education in this article assumes that for quality to be realized there needs to be a clear understanding of the responsibilities of various stakeholders at each of the different levels of the education system. 
Our conceptual framework for quality of education in schools was developed as part of a larger study on the development of an SSE framework for classroom quality in Zimbabwean primary schools. The conceptual framework proposed here is multi-dimensional in nature and based on operational experience by the authors with studying Zimbabwean and South African education systems' performance in general, and particularly, quality of education in schools. Design research, a systematic study of designing, developing, and evaluating educational interventions as solutions to educational problems (Plomp, 2009), was used in the development process of an SSE framework. Design research was considered as a suitable research design for the study because it aims at pursuing new, novel, and socially constructed solutions to problems, through generating design principles, which are both theoretically supported and practically tested (De Villiers, 2005). Design research was compatible with the study's objectives since it aimed to develop an SSE framework for evaluating the quality of education in Zimbabwean primary schools. Through developing an SSE framework, we also managed to come up with a framework for quality of education in schools which we report here. The development of a proposed framework for quality of education in schools was an attempt to gain a deeper understanding of quality of education in schools which would be monitored and evaluated using an SSE framework. A preliminary phase in the larger study on the development of an SSE framework revealed that participants' main understanding of quality of education in schools was in terms of students' achievement in academic subjects (Garira, 2015). This also confirms Williams' (2001) assertion that quality of education is better understood by many in terms of its output than can be done in any other aspect. However, student achievement should not be thought of in terms of achievement in academic subjects only. It should also be viewed in terms of students' cultural heritage, social preparation, personal development (Thijs \& Van den Akker, 2009), and other aspects (see also Figure 1) to help total development of students. The proposed conceptual framework for quality of education reported here was developed through a review of relevant literature as well as existing frameworks. Figure 1 presents a proposed conceptual framework for quality of education in schools.

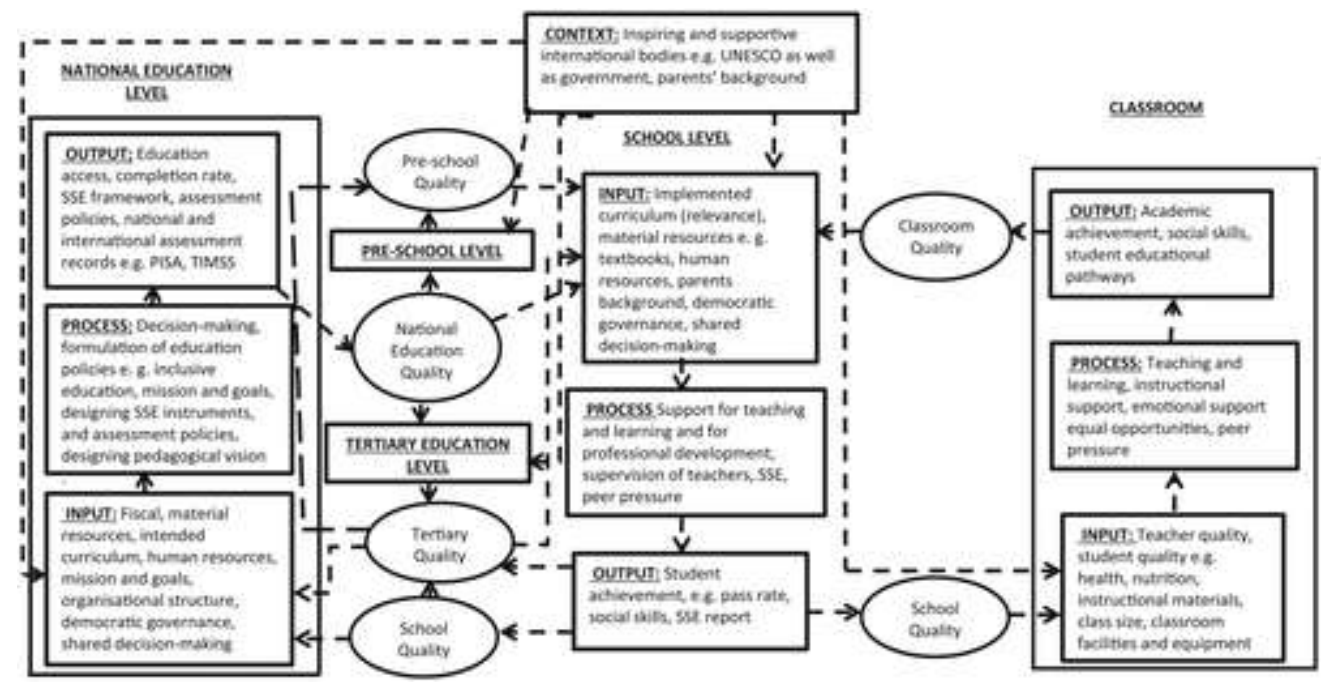


Vol. 5, Issue.1, Jan-Feb 2022, p no. 08-20

\section{Figure 1. The proposed unified conceptual framework for quality of education in schools.}

Our proposed conceptual framework for quality of education in schools is among the first frameworks for quality of education to use a systemic approach in conceptualizing quality of education, where components of quality of education (inputs, processes, and outputs) are considered at all the levels of the education system at once. It places substantial responsibilities to various stakeholders in the education system in terms of supplying inputs and the processes they are expected to carry out for quality educational outputs to be realized, which is discussed in the next section.

\section{The Context}

In our proposed conceptual framework for quality of education, the context provides inputs to all levels of the education system (national, tertiary, pre-school, and school; see Figure 1). The context may include the government, international bodies such as UNESCO and UNICEF, and other social structures with interest in education which may include parents and other civic and private organizations (see Figure 1). The context also provides inputs directly to the classroom. This may be in the form of exercise books and other school stationary which parents buy for their children. Parents may also provide inputs directly to the classroom by helping their children with homework. In its framework for understanding education quality, UNESCO (2004) emphasized the importance of the context for quality of education to be realized. Therefore, the context plays a crucial role in education in that it provides enabling conditions for schooling (Scheerens, 2004).

\section{The National Education Level}

This level comprises the national head office of the education system, the provincial, and the district levels (South African Department of Education, 2009). In our proposed conceptual framework for quality of education in schools, Figure 1 shows that the national education level receives inputs from the context. After receiving the inputs, some processes happen at this level. These processes may include decision-making on various aspects of education such as the formulation of education policies, designing pedagogical vision, designing assessment policies, designing educational mission, vision, and goals (Garira, 2015) (see Figure 1). Other processes should also involve designing and development of SSE frameworks for use in evaluating and monitoring the quality of education in schools (see Figure 1). These processes produce outputs, which are highlighted in the conceptual framework as education access, completion rate, SSE instruments, among others (see Figure 1). These outputs, put together, comprise the national education quality (see Figure 1). Most of the outputs at the national level of the education system are given to institutional levels (tertiary, school, and pre-school) as an input (Garira, 2015) (see Figure 1). These three institutional levels, in turn, give their outputs to their respective classrooms as inputs. Research has shown that an education system that works together with the other levels of the education system may offer high-quality learning opportunities (Garira et al., 2019; Lewis \& Pettersson, 2009). Although the national level of the education system is not the focus of this article, it is an essential level of the education system for it provides inputs and other 
enabling conditions for effective teaching and learning to take place in schools (Scheerens, 2000). The national level of the education system also designs and develops the intended curriculum which will be given to schools for implementation together with other inputs. The different levels of the education system should work together to offer learners high-quality learning opportunities.

\section{The Tertiary Education Level}

In our proposed conceptual framework for quality of education, the input, process, and output details are not provided for the tertiary level in Figure 1, because this level is not the focus for quality improvement in this article. However, quality of education at this level in terms of inputs, processes, and outputs affects and is in turn affected by the quality of education of the other institutional levels (pre-school and school levels) as well as the national education level (see Figure 1). The tertiary education level, which includes colleges (including teacher education colleges) and universities (Akareem \& Hossain, 2012), receives inputs from the national education level which may include human and other material resources. Some processes happen at the tertiary education level, and this will produce an output labeled as tertiary quality (see Figure 1). This output, mainly consisting of human resources and knowledge, will be given as an input to the school and the pre-school levels, (see Figure 1), as graduates of universities and teacher education colleges are the teachers and leaders in the schools. Tertiary quality is also fed back to the national level, because this level of the education system provides manpower for the labor market as well as research and innovation outputs. Although the realization and improvement of tertiary quality and the pursuit of excellence may be the responsibility of higher education institutions themselves (Houston, 2008), other levels of the education system also contribute to this quality (see Figure 1).

\section{FINDINGS AND DISCUSSIONS}

\subsection{A Comparative Overview of the Framework on the Teacher Education programmes}

According to Barrows and Vlasceanu (2003),

The basic aim of every teacher education programme is to educate competent teachers and to develop the necessary professional qualities to ensure lifelong teaching careers for teachers. Behind this aim is the belief that initial teacher education is of paramount importance and that any defects appearing in the programme will have consequences that will be extremely difficult to correct later.

With reference to Finland, the philosophy behind her Teacher Education framework is based on the research which identified three key areas namely as; the theory of education, pedagogical content knowledge, and subject didactics and practice (UNESCO, 2003). These elements are directly related to the interaction, and the main organizing theme, from the initial incept of the course to the end. Contrary to the international standards of initiating reforms on teachers education programme, the 
Kenyan TSC came up with a document titled "Framework on entry requirements in the teaching service". The commission justifies its recommendations on the basis that it is constitutionally mandated to review entry grades to the teaching service, geared towards professionalizing the teaching service and improving the quality of education (Republic of Kenya, 2010). TSC therefore made recommendations affecting all the 5 levels of Teacher Education and training in Kenya. These are Early Childhood Development Education (ECDE), Primary Teacher Education (PTE), Primary Teacher Education in Special Needs Education (SNE), Diploma in Technical Teacher Education and Degree Teacher Education programme. The minimum qualification for entry into teaching in Kenya at all levels was reviewed upwards to a Diploma in Education, as opposed to the previous, certificate in Education, that was to be abolished (TSC, 2020).

Conversely, the TSC recommends that the prospective graduate teachers need to undertake Postgraduate Diploma in Education (PGDE) for one year, to prepare them in pedagogy and other professional courses such as Educational Psychology, History of Education and Educational Management. A curriculum for Teacher education at all levels shall be developed by the Kenya Institute of Curriculum Development (KICD) and assessment at all Teacher Education levels shall constitute both formative and summative evaluation. This in itself contradicts the new Higher Education Legal Framework of Dec 2012. The new Higher Education legal framework was put in place to legalize all the activities of CUE. The establishment of CUE was to necessitate the management of University programmes in Kenya. In essence, CUE was mandated to liaise with the public sector in developing a national manpower strategy (Sifuna \& Oanda, 2014). Even though TSC is enshrined in the 2010 Kenyan Constitution, its mandate does not validate its haphazard recommendation to review the Teacher Education programmes, while disregarding the established procedure and legal processes. For instance, if the said Diploma and Degree in teacher education courses were demand driven, then it was expedient for them to engage CUE. Could it be that absolute power corrupts in action by the TSC? Critically, CUE is meant to engage with the professionals and education industry players in running of university programmes so as to align the quality of graduates with the needs of the job market. Shockingly, the disregard by the TSC to have sound dialogue with CUE but rather chose to engage with the Deans in the universities' Schools of Education is wanting. Could it be a state of desperation in having their way to soothe their ego that was in play?

Regarding the entry requirements, students intending to pursue Diploma in ECDE should have scored a minimum Mean Grade of C (Plain) in the Kenya Certificate of Secondary Education KCSE) examination, up from the previous Grade D+ (Plus) requirement for the Certificate Course which ought to be declared redundant. Certificate in Primary Teacher Education training would be replaced by the Diploma Education course, with minimum entry requirement of Mean Grade C (Plain) in the KCSE examination and Grade $\mathrm{C}$ (Plain) in all the cluster subjects. In addition, the applicant should specialize in one Foreign Language and one Indigenous Language. They should also show interest and experience in working with children, demonstrate empathy for children. 
Minimum entry requirements for students intending to pursue Diploma in Secondary Teacher Education would be a Mean Grade of C+ (Plus) in the KCSE examination and Grade C+(Plus) in three teaching subjects. This course would be offered on a demand basis and applicants should also demonstrate empathy with adolescents.

The Primary Teacher Education Certificate Course in Special Needs Education would be replaced by a Diploma course. The minimum entry requirements would be Mean Grade C (Plain) in the KCSE examination and Grade $\mathrm{C}$ - (Minus) in all the subject clusters they intend to specialize in. The candidate should show interest and experience in working with children with special needs and disabilities, empathize with persons with Special Needs and disabilities.

Certificate in Technical Teacher Education would be abolished and replaced with Diploma in Technical Teacher Education. The minimum entry requirement would be Mean Grade of C+ (Plus) in the KCSE examination and Grade $\mathrm{C}+$ in three teaching subjects. Applicants should also demonstrate interest and experience in working with children with Special Needs and disabilities and also demonstrate empathy with them. The four-year Bachelor of Education Degree course would be remodeled to either B.A. or B.Sc. with a Postgraduate Diploma in Education (PGDE). Although the minimum entry requirement remains at Mean Grade $\mathrm{C}+$ (Plus), the duration would be three years for subject content and one year for PGDE. Teachers at this level would specialize in three subjects, as opposed to the current Bachelor of Education (B.Ed.), in which they specialize in two teaching subjects. However, the teaching subjects would be offered on demand basis. Apart from the academic requirements, applicants should show empathy with adolescents.

The minimum entry requirement for students intending to become teacher educators in Primary and Secondary school training colleges would be required have attained a Mean Grade of C+ (Plus), with Grade B- (Minus) in three teaching subjects. It would be a three-year B.A. or B.Sc. and a one-year PGDE in Teacher Education. The students would specialize in three teaching subjects as opposed to the current arrangement where they take two.

For those teachers who are already trained but not yet employed by TSC, there is provision for the Post Training Certificate Course. This course would be offered for a duration of nine months, targeting all trained teachers and it would be offered either during school holidays, by Distance or Online Learning. During the course, teachers would be required to undertake microteaching in order to refresh their pedagogical skills.

\section{ANALYSIS}

As observed in section 2, TSC argues that its recommended changes on the Teacher Education programmes are in line with its constitutional mandate. However, the procedure undertaken in 
instituting the recommendations casts doubt on the practicability, authenticity and intention of the whole exercise. The Teacher Education in independent Kenya has been in existence since the year 1965, while the B.Ed. Degree course started being offered in 1970 (Otiende, 1992). For all these decades these programmes have been in place and if there is need to review them, then TSC should engage CUE on the way forward. This is because, it is part of CUE's function to oversee and approve the new university programmes. Furthermore, CUE is mandated to advise the government on the university policy; evaluate the state of university education programmes and ensure that they comply with the set standards. In view of the CUE mandate regarding the university education programmes, the proposed irregular review of these university Bachelor degree programme by TSC is an issue of great concern. Whereas Article 43 of the TSC Code of Regulations mandates TSC to review the entry qualifications for various levels of Teacher Education programmes, its role is advisory, as opposed to implementation, as set out in its Teacher Education Framework (TEF) document.

The role of reviewing and approving curricula programmes lies with the Kenya Institute of Curriculum Development (KICD). KICD receives, considers develops and reviews curriculum proposals from basic up to tertiary institutions of education (Republic of Kenya, 2013). However, as already observed by (Githiga, 2012), KICD's role of curriculum review excludes the university. Therefore, TSC's recommendation that KICD should develop university curriculum disregards the mandate of the University Senate.

Remodeling of the B.Ed. programme and the recommendation that Degree and Diploma courses by TSC be offered on demand basis is not grounded on any empirical evidence to warrant it. In essence, not all trained teachers get employed by TSC. Whereas some land teaching jobs abroad, some get employed in other sectors such as the civil service. It is hence illogical for TSC to regulate the number of teachers to be trained within a given period. Furthermore, TSC's recommendation that student teachers be assessed by external examiners during their teaching practicum is equally illogical. No authentic concern has been raised against the teacher educators' competence regarding the teaching practicum assessment that warrant their replacement with external examiners. A teacher educator imparts knowledge and skills in the learner and in turn expects them demonstrated during the teaching practicum. All along student teachers have been assessed by their tutors and they have done performed exemplary. What has become of internal examiners to warrant their replacement by external examiners is a recommendation that TSC has not justified. Student teachers ought to be assessed by their tutors in order to ascertain the extent to which their students implement the skills and knowledge they have acquired.

Whereas the academic qualifications for admission to the various Teacher Education courses are elaborate, there are some entry requirements which are not measurable due to their psychological nature. Notable among them are the requirements for one to show interest in working with young children and demonstrate empathy in order to be considered for a Diploma course in ECDE. This raises 
questions as to how such psychological attributes can be measured before one is enrolled in the course. Additionally, one ought to have studied one Foreign Language and one Indigenous Language as a prerequisite entry requirement to the course. It is equally unclear as to what TSC refers to as "Foreign Language" and "Indigenous Language," given that English, the medium of instruction in Kenya, is a Foreign Language whereas Kiswahili, one of the National Languages is Indigenous. Both languages are taught as compulsory subjects at the elementary level of education. In Kenya, the Language of Instruction policy requires learners to be taught in the language of the catchment areas in Grade One up to Grade Three, for the schools in the rural setup. In urban areas, Kiswahili is used as the Language of Instruction in the same grades (Kenya Institute of Education, 1992). It however remains unclear the type of languages TSC is referring to as 'foreign,' and 'indigenous.'

Admission to the Diploma in Education (SNE) requires a candidate to demonstrate empathy for persons with special needs and disabilities while those intending to pursue Diploma and Degree courses in Secondary Education ought to demonstrate the ability to empathize with adolescents, raising questions on how this attribute can as well be measured.

In a nutshell, TSC's recommendation to review the Teacher Education programme did not comply with the laid out procedures. In the first place, TSC's role is advisory as far as curriculum review is concerned, and that university curriculum review is a preserve of the respective University Senates. Furthermore, TSC's recommendations are not informed by any research finding(s) to necessitate their implementation. KICD (n.d.) establishes the standard procedure for curriculum review and development. The first and most fundamental is the Needs Assessment. This entails a survey conducted to establish any gaps in the existing curriculum or programme. The findings inform the need to kick start the review process, based on the identified gaps. There is no tangible problem identified with the current Teacher Education arrangement to warrant any form of review, hence TSC's recommendations are not informed by any research findings. Apart from overlooking this fundamental requirement, TSC illegally overstepped its mandate by taking over the role of KICD in recommending review of the Teacher Education curriculum. It is from the cited flaws in the whole process that this paper proposes adoption of morally and internationally acceptable approach in the teacher education review process, as spelt out by KICD. This entails needs assessment, policy formulation, piloting, preparation of curriculum implementers, implementation, monitoring and evaluation.

\section{CONCLUSION}

Being a constitutional commission with clearly defined functions, TSC is mandated to maintain the standards of education from the elementary up to tertiary levels of education save for university education. However, the proposed reforms in Teacher Education programmes were done in pure disregard of the law and the laid out procedures. In conducting such reforms, it is incumbent upon TSC to liaise with the stakeholders in the education sector such as KICD, CUE and teachers, who are the curriculum implementers so that due process is adhered to. 


\section{International Journal of Education and Social Science Research}

Vol. 5, Issue.1, Jan-Feb 2022, p no. 08-20

\section{REFERENCES}

Barrows, S. L \& Vlasceanu, M. B (2003). "Institutional Approaches to Teacher Education within Higher Education in Europe: Current Models and New development." Studies on

Higher Education. UNESCO CEPES. ISBN 92-9069-173-X

Githiga, G. (2012). Procedure of curriculum change in Kenya. Retrieved 17, July 2021 from https://githigagitogo.wordpress.com/2012/11/08/procedure-of-curriculum-change-inkenya/

Kenya Institute of Education. (1992). Primary Education Syllabus Vol. 1. Nairobi: Kenya institute of Education.

KICD. (n.d.). Curriculum development cycle. Retrieved 17, July 2021 from https://kicd.ac.ke/ curriculum-reform/curriculum-policy

Oiende, J. E. (1992). Education and development in Kenya: A historical perspective. Nairobi: university of Nairobi Press.

Republic of Kenya. (2010). The Constitution of Kenya. Nairobi: National Council for Law Reporting.

Republic of Kenya. (2012). Universities Act No. 42 of 2012. Nairobi: National Council for Law Reporting.

Republic of Kenya. (2013). The Kenya Institute of Curriculum Development. Nairobi:

Government Printer.

Republic of Kenya. (2015). The Teachers Service Commission Code of Regulations for

Teachers. Nairobi: Government Printer.

Tella, S. (1996). "Teacher Education in Finland: Present and Future Trends and Challenges", Studia Pedagogical II

TSC. (2020). Framework on entry requirements in the teaching service. Unpublished proposed recommendations to review the teacher Education programmes in Kenya. Nairobi. 